\title{
Health care stakeholder perspectives regarding the role of a patient navigator during transition to adult care
}

\author{
Gina Dimitropoulos ${ }^{1,2,3^{*}} \mathbb{D}$, Elizabeth Morgan-Maver ${ }^{4}$, Brooke Allemang ${ }^{1}$, Kyleigh Schraeder ${ }^{3,5}$, Shannon D. Scott ${ }^{6}$, \\ Jorge Pinzon ${ }^{3,5}$, Gail Andrew ${ }^{7}$, Gregory Guilcher ${ }^{5,8}$, Lorraine Hamiwka ${ }^{5,9}$, Eddy Lang ${ }^{10}$, Kerry McBrien ${ }^{11,12}$, \\ Alberto Nettel-Aguirre ${ }^{3,5,11}$, Daniele Pacaud ${ }^{3,5,13}$, Lonnie Zwaigenbaum ${ }^{7}$, Andrew Mackie ${ }^{7,14}$ and \\ Susan Samuel $3,5,9,11 \dagger$
}

\begin{abstract}
Background: Transition to adult care represents a vulnerable period for young people with special health care needs as they navigate multiple life transitions and developmental issues. Patient navigators are a promising intervention designed to facilitate the transfer from pediatric to adult care. However, consistent definitions, key tasks, roles and responsibilities are lacking in guiding the scope of practice and the implementation of patient navigators.
\end{abstract}

Methods: Fundamental qualitative description was utilized in this study to identify perceptions from health care providers about implementing a patient navigator service for young people with special health care needs in transition to adult care. A purposive sample of health care providers with a variety of backgrounds within pediatric and adult systems in Alberta, Canada were recruited. Semi-structured interviews with participants were analyzed using thematic analysis to inductively identify perceptions regarding the role of patient navigators.

Results: A total of 43 health care providers highlighted the need for a patient navigator service to encompass 4 key stages for young people with special health care needs transitioning from pediatric to adult services: (1) identification of young people with special health care needs and families requiring support, (2) preparation for transfer, (3) health system navigation and, (4) post-transfer support.

Conclusions: The results of this qualitative study provide guidance for the development of patient navigator interventions for young people with special health care needs, as well as provide support for current transition services offered across Canada.

Keywords: Adolescents, Young adults, Transition age young people, Chronic disease, Qualitative research, Patient navigator $(\mathrm{PN})$, Special health care needs (SHCN)

\section{Background}

Young people with complex or special health care needs $(\mathrm{SHCN})$, are defined as those who acquire, or are at increased risk for, a chronic physical, mental health and/or developmental (including cognitive and sensory

\footnotetext{
* Correspondence: gdimit@ucalgary.ca

${ }^{+}$Andrew Mackie and Susan Samuel denotes senior authorship

${ }^{1}$ Faculty of Social Work, Professional Faculties 4212, University of Calgary,

2500 University Dr. NW, Calgary, AB T2N 1N4, Canada

${ }^{2}$ Department of Psychiatry, University of Calgary, Calgary, Alberta, Canada

Full list of author information is available at the end of the article
}

impairment) condition(s) [1, 2]. These young people often require transfer to adult health care services. Currently, the post-transfer period is associated with significant loss to follow up in medical care. Many young people and their families are unprepared for the transfer and face challenges navigating adult health care services [2-4]. Suboptimal transfer to adult care may lead to increased health care utilization and patient's deterioration in health [510]. A coordinated and planned health service transfer to adult care is necessary to ensure optimal outcomes [2].

C The Author(s). 2019 Open Access This article is distributed under the terms of the Creative Commons Attribution 4.0 International License (http://creativecommons.org/licenses/by/4.0/), which permits unrestricted use, distribution, and reproduction in any medium, provided you give appropriate credit to the original author(s) and the source, provide a link to the Creative Commons license, and indicate if changes were made. The Creative Commons Public Domain Dedication waiver (http://creativecommons.org/publicdomain/zero/1.0/) applies to the data made available in this article, unless otherwise stated. 
Various interventions have been recommended to support young people with SHCN during their transition from pediatric to adult oriented health care services [11, 12]. The Canadian Association for Paediatric Health Centres in its Guideline for Transition from Paediatric to Adult Care recommends that health care organizations implement transition planning by care coordinators/navigators [2]. In the literature, the role of facilitating transition of care has been ascribed to individuals with varied roles, including: transition care coordinators [13], patient navigators [9], community health workers [14], and case managers [15]. However, these terms are used interchangeably in the literature and distinct definitions of each role are poorly articulated [11].

Patient navigators (PNs) have been used in populations with a variety of health conditions [13, 15-17], primarily in adult settings, to support care coordination and sustained engagement with health services [18]. Care coordination and transition intervention models have been piloted to support children with medical complexity and their families utilizing pediatric nurses acting as case managers and transition educators [19-21]. The interventions described in these studies focused on education initiatives, promoting self-management, resource navigation and assisting with appointment scheduling with providers. Results showed that these models reduced hospitalization costs, family out-of-pocket costs, length of stay in hospital, improved patient satisfaction, reduced likelihood of delays accessing adult care and improved knowledge and self-management skills [19, 20, 22].

Intervention studies demonstrate that the use of coordinators improves appointment attendance, medication adherence and reduces loss to follow-up in specific patient populations. A recent Canadian environmental scan of existing navigation services for patients 0-19 years identified 23 pediatric PN programs across the entire country [23]. Despite the emerging use of PNs, there remains a lack of consensus on their role, responsibilities, and qualifications in the context of supporting young people with $\mathrm{SHCN}$ navigating transition to adult care $[24,25]$. The purpose of this paper is to describe health care providers' perceptions about the PN role in supporting young people (including adolescents and young adults aged 13 to 24 years old) with SHCN during transition to adult care including scope, responsibilities and tasks. Key stakeholders are defined as health care providers, policy makers and administrators in the pediatric and adult systems in Alberta with expertise in health care transition.

\section{Methods}

This study adheres to the COnsolidated criteria for REporting Qualitative research (COREQ). The researchers in this study employed fundamental qualitative description with the goal of describing rather than interpreting data. Fundamental description is commonly employed to garner information from applied health care contexts that may be used to inform service and practice-based changes $[21,22]$. We intentionally employed this approach to glean what practitioners are employing in practice that may be beneficial to young people in the health care system.

\section{Population and setting}

Participants were recruited from primary, tertiary and community-based health settings in the province of Alberta, Canada. A total of 37 individuals expressed interest in this qualitative study and were screened for participation. Three potential participants could not be scheduled for an interview within the specified recruitment period, therefore, 34 key stakeholders were included in the final sample. Participants' primary work locations were based in two different city centres (Calgary (65\%) and Edmonton (27\%)) as well as semi-urban/rural areas (9\%). The majority of participants (Table 1) were female (79\%), between 40 and 60 years of age $(82.4 \%)$ and worked with adolescents (59\%), both adolescents and adults (21\%) or adults only (18\%). Occupations of the participants included administrators/policy makers $(n=13)$, direct service providers $(n=27)$ and clinicians primarily conducting research in their clinical setting $(n=2)$. Those who identified as researchers in this study were also clinicians involved in direct service provision to young people with chronic conditions. Five transition coordinators were interviewed for this study who primarily worked in the pediatric sector.

\section{Sampling and recruitment}

We used purposive sampling [26] to identify key stakeholders connected to service delivery of pediatric and adult health care within Alberta Health Services, the health authority responsible for the majority of health service delivery for Albertans. Key stakeholders referred to policy makers, administrators, researchers, or clinicians who work in pediatric and/or adult systems. At the start of study, two authors (GD, SS) presented the research project to a provincial network focused on transition issues for young people in Alberta [27] and recruitment material was distributed to attendees (including clinicians, policy makers, and researchers) through email. Interested stakeholders contacted researchers expressing their interest to participate in the study. A member of the research team reviewed the study purpose, data collection methods and data storage procedures. They were informed that all transcripts would be de-identified in order to protect and maintain the confidentiality of all participants. Participants then signed informed consent forms. Participants were offered the opportunity to participate in a focus group 
Table 1 Characteristics of key stakeholders participating in focus groups and interviews

\begin{tabular}{|c|c|}
\hline Characteristic & $\begin{array}{l}\text { No. (\%) of participants } \\
n=34\end{array}$ \\
\hline \multicolumn{2}{|l|}{ Gender } \\
\hline Female & $27(79 \%)$ \\
\hline \multicolumn{2}{|l|}{ Age } \\
\hline$<40$ & $3(9 \%)$ \\
\hline$>40$ & $28(82 \%)$ \\
\hline \multicolumn{2}{|l|}{ Work location } \\
\hline Calgary city & $22(65 \%)$ \\
\hline Edmonton city & $9(27 \%)$ \\
\hline Semi-urban/rural Alberta & $3(9 \%)$ \\
\hline \multicolumn{2}{|l|}{ Participant roles } \\
\hline Policy maker/Administrator & $13(38 \%)$ \\
\hline Family advisor & $1(3 \%)$ \\
\hline Physician & $5(15 \%)$ \\
\hline Nurse & $8(24 \%)$ \\
\hline Social Worker & $4(12 \%)$ \\
\hline Dietician & $4(12 \%)$ \\
\hline Researcher & $2(6 \%)$ \\
\hline Transition Coordinator & $5(15 \%)$ \\
\hline \multicolumn{2}{|l|}{ Years of experience in role } \\
\hline Less than 5 & $5(15 \%)$ \\
\hline 5 to 10 & $8(24 \%)$ \\
\hline 11 to 19 & $7(21 \%)$ \\
\hline More than 20 & $14(41 \%)$ \\
\hline Identified as being in leadership position & $9(27 \%)$ \\
\hline \multicolumn{2}{|l|}{ Working with primarily } \\
\hline Adolescents only & $20(59 \%)$ \\
\hline Adults only & $6(18 \%)$ \\
\hline Adolescents and adults & $7(21 \%)$ \\
\hline \multicolumn{2}{|l|}{ Work setting } \\
\hline Primary care (adolescents) & $7(21 \%)$ \\
\hline Primary care (adults) & $2(5 \%)$ \\
\hline Tertiary care (adolescents) & $19(56 \%)$ \\
\hline Tertiary care (adults) & $6(18 \%)$ \\
\hline Community-based setting & $6(18 \%)$ \\
\hline
\end{tabular}

during specific dates and times. If they were unable to participate in the scheduled focus group, they were offered a one-one-one interview at their preferred date and time. The interviews were offered by telephone or in person at the participants' convenience. The same interview guide was used in both focus groups and one-on-one interviews and no differences emerged in the demographics including professional backgrounds of participants who were involved in the interviews versus focus groups, as demonstrated by the diversity of participants represented in the focus groups.

\section{Inclusion and exclusion criteria}

Inclusion criteria for participation were: a) provide direct or indirect services to individuals between ages of 13 to 24 with a chronic health condition and $\mathrm{SHCN}$ in Alberta; and, b) the provision of services to support transfer of care from pediatric to adult services. We excluded practitioners who cared for patients with mental health and neurodevelopmental disorders solely, as these individuals typically work outside tertiary care centres in community-based organizations. A brief screen for inclusion was facilitated by a team member.

\section{Data collection procedures}

A semi-structured interview guide was developed by the author (GD) with input from co-authors and local experts in transition. Their backgrounds included a diverse expertise in social work, community health sciences, adolescent mental health, and youth transition to adult care. The guide was piloted with two pediatric health care providers. This guide was refined based on the pilot interviews and used for individual interviews and focus groups (Additional file 1). All focus groups were conducted by one of the authors (GD or EM) within one pediatric tertiary care hospital (Alberta Children's Hospital), and were approximately $90 \mathrm{~min}$. Interviews were conducted by two authors (GD, EM) in-person or by telephone, lasting $40-60 \mathrm{~min}$.

\section{Analysis}

Qualitative interviews and focus groups were audiorecorded and transcribed verbatim. Data analysis was conducted concurrently. The two independent analysts paid close attention to the descriptions that participants in the individual interviews and focus groups provided to questions about the role of the patient navigator. Upon review of all transcripts, it appeared that no significant differences were uncovered in participant responses between the interviews and focus groups, therefore, the transcriptions from both methods of data collection were analyzed simultaneously. In our study, combining focus group and interview data enhanced the trustworthiness of our findings given the convergence of central themes amongst the participants [28]. The team discontinued recruiting participants due to the strong quality of the dialogue when it was agreed that the information obtained achieved sufficient power to fulfill our study aim [29].

The team used thematic analysis and systematically adhered to the six steps described by Braun and Clark [30]. We employed an inductive approach given the paucity of literature on health care providers' perceptions of 
the patient navigator in supporting YSHCN to transition to adult services. First, two coders (EM, BA) immersed themselves in the data by reading and re-reading transcripts in order to familiarize themselves with the data. Second, using memos, the team documented their impressions of the data and independently generated and assigned codes to the qualitative data. Codes refer to words that describe the researchers' thoughts about ideas that emerged within and across the data [31]. Third, the data were collated based on codes initially established. The team debriefed about the codes generated by each coder and only codes that received consensus were included. Codes were grouped into major themes and given titles, in order to better represent the data. Fourth, emergent themes were reviewed and refined to ensure they were representative of the data. Next, the themes were defined, named and further refined while identifying subthemes where applicable. Finally, for the sixth step, the research team analyzed and described the themes and subthemes and created a visual concept map [32].

Several steps were undertaken to maximize methodological rigour by following the guidelines for publication of qualitative research [32]. First, we worked with experts in transitions and chronic illness to develop an interview guide. We used thick descriptions in our results section by integrating direct quotes from participants to illustrate the concepts and themes generated [33]. In qualitative research thick description refers to the utilization of quotes that provide a visual description or depiction of the themes. Throughout the data analysis process, the principal investigator facilitated weekly peer debriefing with the research team (two qualitative research assistants) to provide a forum for reflection of the codes that were emerging from the data. Member checking was used to obtain feedback from others in similar roles. Finally, a concept map was created to provide underlying structure of the data, and exemplar quotes are provided to illustrate the verbal narrative of themes. Transcripts were not returned to the participants for comment and participant checking was not performed.

\section{Results}

\section{Final sample}

Twenty-four individual interviews, and 3 focus groups of 2, 3 and 5 participants each were conducted between July and November 2017. Although focus groups were small, our research team facilitated discussions between participants regardless of the size and encouraged varying opinions to each other's responses to the same questions.

\section{Findings}

The overarching theme emerging from the data was a perceived need for PNs to be involved at multiple stages of the transition experience. Participants identified four stages of PN involvement: [1] identification of young people with $\mathrm{SHCN}$ and families requiring support, [2] preparation for transfer; [3] health system navigation [4] post-transfer support. Figure 1 provides a visual depiction of the stages.

Themes and sub-themes from the analysis are described with exemplar quotes below. Quotes are referenced by occupation and an identification number.

\section{Identification of young people at risk}

Participants shared that that a PN should not be universally available to every young person who is transitioning to adult care. "I don't think all kids need it [navigator]" (nurse, participant 02), providing services to those who need it the most was a common theme across participants. However, it is important to "come up with some criteria of who are we really looking for, who is at risk of having a poor transition" (nurse practitioner, participant 08).

\section{Identifying the most complex young people}

Participants recommended screening young people and families for complex needs, "kids who have multiple diagnoses," (nurse practitioner, participant 08) and "mental health comorbidities," (physician, participant 14), whom they believed greatly needed additional emotional and instrumental support. Participants also commented that a PN should provide support to young people with developmental disabilities, precarious housing, poverty, mental health problems, substance abuse, and limited natural supports. "Clear red flags- so I think if you're in the judicial system, if you're in the foster system, if you have no place to live, the street, those are general but I think they are applicable. If you have a special need, I don't know how you want to take care of your basic needs ..." (physician, participant 14).

All participants reported that young people and families who are unfamiliar with the Canadian health care system would benefit from the service. As one participant stated: "families .... who haven't grown up here. English as a second language, maybe recently immigrated to Canada, have no social supports, they are struggling on lots of different socioeconomic levels" (nurse, participant 01). Further, young people "thrown into this world of a new diagnosis and you don't have a clue [of] the things you need," (nurse, participant 01) at the time of transfer were also perceived to need support from a PN. Participants also identified a critical need to support young people who frequently use the emergency department. "And potentially if I know what the vision is, if there are flags that this person is at risk, if there isn't some oversight and they are showing up in emerg or having admissions, how can they potentially support what needs to 


\section{ROLE OF THE NAVIGATOR}

\begin{tabular}{|c|c|}
\hline $\begin{array}{l}\text { Identifying at } \\
\text { risk youth }\end{array}$ & $\begin{array}{l}\text { i. Identifying most complex youth } \\
\text { ii. Tailoring the support of the PN based on need }\end{array}$ \\
\hline Preparation & $\begin{array}{l}\text { i. Key PN tasks in preparing youth for transition to adult services } \\
\text { ii. Addressing developmental issues with youth and their families }\end{array}$ \\
\hline $\begin{array}{l}\text { Health system } \\
\text { Navigation }\end{array}$ & $\begin{array}{l}\text { i. Resource navigation and connection to services } \\
\text { ii. Primary care engagement }\end{array}$ \\
\hline $\begin{array}{l}\text { Post-transfer } \\
\text { support }\end{array}$ & $\begin{array}{ll}\text { i. } & \text { Length and duration of post-transfer PN involvement } \\
\text { ii. } & \text { PN situation in both pediatric and adult systems } \\
\text { iii. } & \text { Assist with adaptation and actively follow-up in adult system }\end{array}$ \\
\hline
\end{tabular}

Fig. 1 Conceptual Map- stages defining the role of the patient navigator

happen in a bit more of a proactive way" (administrator, participant 09).

\section{Tailoring the support of the PN based on need}

Participants endorsed tailoring support to each patient and their unique circumstances once a PN is employed. The support could vary from providing educational resources to the provision of more intensive and prolonged support to increase engagement in adult programs for young people who are more complex and disadvantaged. One participant described this idea using the analogy of traffic signs: "If we look at green, yellow and red flags. The green flags are the families who are managing care really well, attending all appointments they are the ones who maybe need some paper resources and figure out early on where do I go for my care when I'm an adult. If we look at the yellow flags, those are... the kids who have multiple diagnoses [and] would be more at a risk because they are going to have to find multiple care teams. And the red flags are the kids who are falling through the cracks already who have higher risk of death or disability if they transition." (nurse practitioner, participant 08). The diversity among PN tasks was summarized as: "teaching, follow up, ensuring supports are in place if needed, answering questions, providing educational material, teaching other staff how to implement some of the basic teachings so it doesn't all fall on one person, incorporating other key members as needed .... And just coordinating everything." (nurse, participant 25).

\section{Preparing for transition}

Participants identified two key tasks of a PN prior to transition; 1) preparing young people and families for transition to adult services and 2) addressing developmental issues with young people and their families to support a successful transition.

\section{Key tasks during preparation}

Participants agreed the PN should carry out transition readiness assessments, and use these assessments to guide the support they provide during the preparation for transitioning to adult care. Common suggestions were that the PNs help young people build their selfadvocacy, self-management and communication skills to prepare for engaging with adult providers. As summarized by a nurse (participant 25): "ideally, [young people] go into the adult world with complete knowledge ... what possible complications that they could have, are able to advocate for themselves, talk to medical professionals, be able to articulate what they need in a clear manner". Several participants articulated the PN act as an adjunct to the clinical team and provide necessary education to the young people about their health condition when knowledge gaps exist, "give them the knowledge and empower them to be more aware of what is going on as opposed to the shock of walking into appointments" (nurse, participant 25) and coach them to effectively communicate their needs to health care providers. PNs can play a role in "making them comfortable with the idea that they are going to be seeing new providers and that they want to help you ... giving them more information about how to ask questions." (nurse practitioner/transition coordinator, participant 15). Participants also advocated that a PN provide education in broad topics (Fig. 2) to prepare for the transition to adult care.

\section{Addressing developmental issues with young people and families}

There was consensus among participants that transition preparation should begin early but this ranged from age 12 to 16 . As a nurse (participant 25) stated: "hopefully eventually in the 14-16 year old range, and working slowly to transition them and help them with that process getting into that adult world." Participants also advocated for a lifespan perspective that facilitates the young person achieving their goals 


\section{Managing chronic disease (self-management) \\ Disease-specific information (complications, symptoms) \\ Drugs/alcohol \\ Sex and relationships \\ $\square$ Self-advocacy \\ $\square$ Communication skills \\ $\square$ Whom to contact during transition \\ $\square$ Renewing prescriptions \\ Insurance coverage}

Fig. 2 Transition preparation education topics

with greater independence. Participants agreed that PNs should work with both young people and parents, but aims shift based on developmental needs, and degree of functioning due to illness and cognitive abilities. One participant proposed: "that it's really dependent on how functional the parents are and what connection they have with their child, and how functional the young adult is and what degree of development. There's enough variability there to have a check-in with clinical staff who work with them and should have a pretty good knowledge of them" (physician/researcher, participant 07). Key responsibilities for preparing young people for transition, including promoting self-management and selfadvocacy skill building, depend on the needs and developmental stage of the young people. One participants shared: "For chronic disease management, it's a continuing process. Because transition is through our whole life. What a kid is able to do at age 12 versus 14 versus 16 is completely different. And what you're trying to do is balance what they are able to do ... and have parents support the rest" (nurse/transition coordinator, participant 15).

\section{Health system navigation}

One of the most common themes identified by participants was the role of the PN in health system and resource navigation and facilitating engagement with primary care.

\section{Resource navigation and connection to services}

Participants described the PN's main involvement as "reaching out to certain systems or at least connecting families," (nurse, participant 01), thus connecting young people to diverse multi-disciplinary services in the community, as summarized in Fig. 3 . The PN represents " $a$ bridge" (administrator, participant 09), "a person ... kind of in the middle" (nurse, participant 01), between pediatric and adult care providers who are often dispersed rather than in one location. One participant (administrator, participant 11) said "it's sort of like you think about a grassy yard on a corner where there is a sidewalk

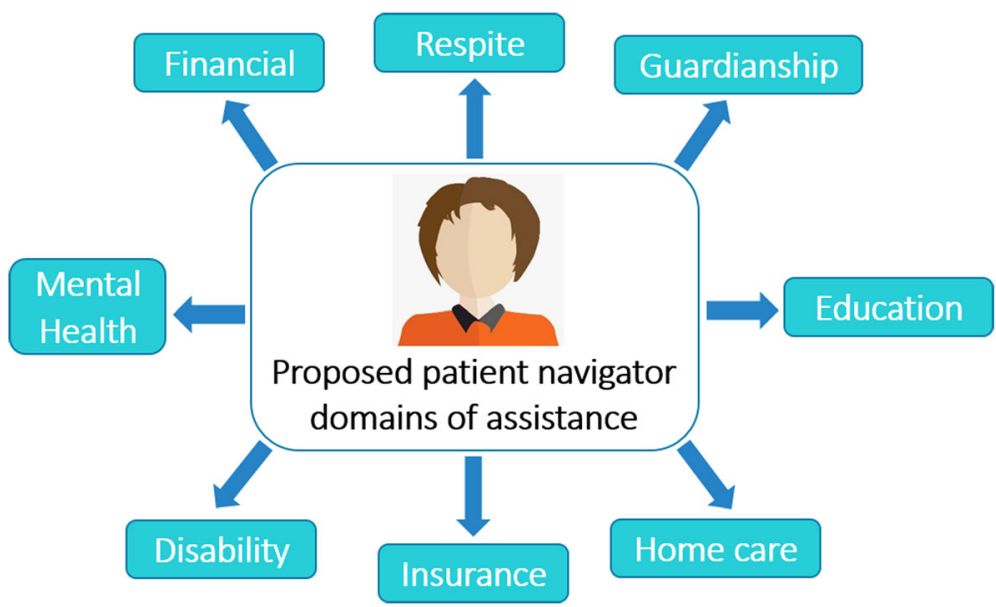

Fig. 3 Proposed domains patient navigators can assist with access 
that turns 90 degrees... I think about those navigators as those people who cross the corners and start to beat down a path."

\section{Primary care engagement}

Participants consistently emphasized that primary care providers ensure a seamless transition by providing continuity of care. As expressed by one participant (administrator, participant 20), "every single one of these transition patients and families should have a primary care physician regardless of how complex they are." Another participant stated, "there's no question that the family doctor is part of the team and they are the anchor for that family." (nurse/transition coordinator, participant 15). Additionally, participants perceived that PNs "should make sure that the patient they are navigating can be settled well in a primary care service" (policy maker, participant 05). Another participant also mentioned the importance of a "medical home" (nurse/transition coordinator, participant 15), as a part of better health care for young people who leave pediatric services. Many also advocated for increased support for primary providers in order to improve their understanding of the unique developmental characteristics of young people with special health care needs. As advocated for by an administrator (participant 09): "Another big piece working with adult partners is helping them understand what are the needs of adolescents versus other adults and seniors".

\section{Post-transfer support}

Support following transfer was considered critical to promote continued engagement and assist with "attachment and adaptation" (administrator, participant 09) of transitioning young people to adult health systems.

\section{Duration of post transfer involvement}

Opinions regarding length and duration of post-transfer PN involvement varied. Some participants expressed views that the PNs' work should not be limited by time and continue until all patient needs have been addressed due to the immense need for continued support in adult health services. An administrator (participant 24) explained, "I think it comes down to resources but I think they should always be involved as long as somebody continues to transition through the system".

Others argued for a prescribed period of intervention; "I would say 2 years after transfer of care. I think we shut it off far too quickly. And the kids that are falling through the gaps, it would be great if they have somebody that they can call ... that contact of trying to scrape those kids off the floor and get them back into health care would really help." (nurse/transition coordinator, participant 15).

\section{PN situation in both pediatric and adult systems}

All participants agreed that PNs should have office space in both pediatric and adult systems as illustrated by this quote: "I think both. I think the navigator should be able to cross the boundary. It's not really a [pediatric] service or adult service. If we're staying in the true sense of a navigator, like providing one on one care coordination it will depend on where that young people is having problems ... I guess they should be able to cut across." (policy maker, participant 05). Many participants expressed a greater need for the PN to work within adult-focused programs, which often lack the resources to implement similar levels of support to patients and families.

\section{Assist with adaptation and actively follow-up in the adult system}

Across all interviews participants discussed the need for the PNs to assist with adaptation to the adult system and conduct follow-up so "that patients are not lost to care" (dietician, participant 03). One participant proposed a PN "would encourage, she would follow up on appointments and making sure people got attached. She would send reminders about appointments, and if people missed them she would encourage them to reschedule" (dietician, participant 03). Some participants stressed the need for a PN to follow up with patients and intervene as necessary to help manage adverse events. As stated by one participant: "it needs to be able to come in and support if things aren't going well, or we can anticipate there being challenges with this child or family" (administrator, participant 09). Many participants added there is a greater need for the PN to facilitate attachment to adult-focused programs since adult providers often lack the time to engage young adults due to limited time and resources.

\section{Discussion}

Participants provided rich and predominantly consistent perspectives regarding the role of a $\mathrm{PN}$ to support young people with $\mathrm{SHCN}$ transitioning to adult care. In our study, participants agreed that "patient navigator" is a term that closely captures and encompasseses the variety of roles that are undertaken by professionals working with young people with $\mathrm{SHCN}$. There was greater variability among participant opinions regarding the age at which transition preparation should begin and the duration of patient navigator support. Screening for case complexity based on medical and mental health comorbidity, transition readiness, and family context were identified as important steps in determining who will have access to the PN. Empowering young people with knowledge and supporting them to take responsibility for their care over time arose across the interviews and focus groups. Provision of developmentally appropriate 
supports, health system navigation and post-transfer assistance were also identified as important themes.

The existing literature broadly aligns with our findings of providing support to populations at risk of poor outcomes [34]; those with complex medical or mental health comorbidity [35], with low health literacy [36], new immigrants [37] and those within complex social situations [38]. Our findings about the patient navigator's role in preparing young people for transition to adult services are similar to those summarized by Luke et al. [23], where existing Canadian programs are described as aiming to promote care coordination, education and emotional support. Many of the proposed key tasks of a $\mathrm{PN}$ in the context of transition preparation (education, transition resource development), also align with previously published transition support programs that achieved favorable system and patient level outcomes $[9,13,15]$. Studies from the patient perspective indicate that adolescents value trusting relationships with health care providers who offer adolescent-focused information and discuss aspects of their lives outside of the illness [39-41]. These concepts arose in the interviews and focus groups, with participants advocating for the PN acting as a bridge to adult providers and offering transition-related education. Having health care providers communicate directly with adolescents regarding self-management and transition planning was also highlighted as a key finding in the literature [39]. This was strongly supported by our study participants who acknowledged the importance of the PN role in offering developmentally-appropriate support. Interestingly, however, the literature suggests some young people report ambivalence about taking increased responsibility for their care [42] which suggests the PN account for the young person's feelings about and readiness for transition in developing a tailored intervention.

Our study adds new information in several areas. These include tailoring support based on the unique needs of young people at the age of transition, and perspectives regarding duration of support posttransfer to adult care. Post-transfer involvement and follow-up with patients in the adult system is well supported in the literature, however, the duration of support and physical location of the PN widely varies among programs, and is poorly defined. A review by McBrien and colleagues (2018) [43] summarized 67 unique programs and showed that intervention frequency can be as little as 1 contact, with only 14 programs providing support for $>12$ months. Many participants in this study thought that PN support should ideally continue as long as needed, but some acknowledged the practicality of resource limitations, citing the PN intervention needs to be time limited. These perspectives come from stakeholders who are intimately familiar with a pediatric patient population where patients have different levels of medical and psychosocial complexity, and also have various developmental stages which are often affected by the underlying disease process itself. The nature and duration of support needs to be individualized and patient-oriented, and flexible to accommodate diversity of patient and family needs.

This study found that the role of the navigator as a coach to help patients develop self-management skills is important. The shift in responsibility from parents (and pediatric health providers) to young people over time is well supported by existing models for young people with chronic health conditions, including the shared management model [44].

Participants in this study highlighted system navigation, specifically connection to services, bridging pediatric and adult systems and engaging primary care supports as a key role for the PN. There is substantial agreement in the literature about the need for PNs to help facilitate young people to access resources particularly in adult care, which tends to be larger and a more fragmented health system than pediatric care [2, 23, 45]. Despite common acknowledgement that all transitioning young people need a primary care provider, many of our participants noted there is a need for increased support and education of primary health care providers in caring for these patients. It is further recommended that training be provided to primary care providers to increase their understanding and management of young adults with complex needs and neurodevelopmental conditions [46]. However, there may be further unique barriers to caring for complex young people in a primary care setting which need to be explored $[47,48]$. Very few of the transition interventions that have been evaluated involve a primary care component [49]. Given time constraints for primary care physicians, we acknowledge that having them play a key role in supporting connection to adult specialists may not be feasible [50-52]. Thus, involving a PN who acts as a liaison between primary and tertiary care is recommended based on our study findings.

\section{Strengths and limitations}

A major strength is that our sample consists of perspectives of those in leadership, policy and executive roles within the transition field. This study has several limitations including a larger sub-group of participants from pediatric rather than adult settings, the absence of psychiatrists, and few participants working primarily in rural or large geographic regions. The participants recruited for this study were also limited to those involved in a provincial network tasked with the goal of examining best practices for children and adolescents with health conditions. Young people and their families were 
not part of the scope of this paper and we acknowledge the importance of youth and family perspectives in health care delivery. Input from these groups is extremely valuable and important in order to implement and maximize the effectiveness of patient navigation. Next steps of this project include a qualitative exploration of the needs and experiences of young people and caregivers in establishing best practices for a patient navigator intervention by way of individual interviews.

\section{Conclusions}

This study explores how patient navigators can support young people with special health care needs and their families to successfully transfer from pediatric to adult care. The findings of this study will help guide the development of a transition navigator role in a diverse health system and will inform future interventional trials to evaluate the effectiveness of PN programs.

\section{Additional file}

Additional file 1: Summary of interview guide. (DOCX $13 \mathrm{~kb}$ )

\section{Abbreviations}

PN: Patient navigator; SHCN: Special health care needs

\section{Acknowledgements}

For the Transition Navigator Trial team: Scott Klarenbach, Gurkeet Lalli, Daniella San Martin-Feeney, Laurel Ryan.

\section{Authors' contributions}

GD, SS and AM are principal investigators of the study. GD and SS presented the research project to a provincial network to facilitate recruitment. GD developed the interview guide with input from SS and AM. GD and EM conducted participant interviews. GD led thematic analysis with BA and EM GD, SS, EM and BA co-wrote the paper. SDS provided qualitative methodology input. GD, EM, BA, KS, SDS, JP, GA, GG, LH, EL, KM, AN-A, DP, LZ, AM and SS (all authors) contributed to the conception of the study and critical revision of the manuscript. All authors read and approved the final manuscript and agree to be personally accountable for their own contributions to the work.

\section{Funding}

The authors acknowledge The Canadian Institutes of Health Research, Maternal Newborn Child \& Young people Strategic Clinical Network, Roy and Vi Baay Chair in Kidney Research, BMO Financial Group Endowed Research Award in Healthy Living, Alberta Children's Hospital Foundation, Stollery Children's Hospital Foundation, Alberta Children's Hospital Research Institute, and Alberta Health Services for their contributions to this project. The funding agencies had no role in the study design, collection, analysis and interpretation of data, in writing or preparation of the manuscript, or the decision to submit the article for publication.

\section{Availability of data and materials}

The qualitative transcripts from this study will not be publicly shared in accordance with participant confidentiality.

\section{Ethics approval and consent to participate}

Ethical approval was obtained from the Conjoint Health Research Ethics Board at the University of Calgary (REB\#17-0568). All participants provided written informed consent.

\section{Consent for publication}

Not applicable.

\section{Competing interests}

The authors declare that they have no competing interests.

\section{Author details}

${ }^{1}$ Faculty of Social Work, Professional Faculties 4212, University of Calgary, 2500 University Dr. NW, Calgary, AB T2N 1N4, Canada. ${ }^{2}$ Department of Psychiatry, University of Calgary, Calgary, Alberta, Canada. ${ }^{3}$ Alberta Children's Hospital Research Institute, Calgary, Alberta, Canada. ${ }^{4}$ University of Calgary,

Calgary, Alberta, Canada. ${ }^{5}$ Department of Pediatrics, University of Calgary,

Calgary, Alberta, Canada. ${ }^{6}$ Faculty of Nursing, University of Alberta,

Edmonton, Alberta, Canada. ${ }^{7}$ Department of Pediatrics, University of Alberta, Edmonton, Alberta, Canada. ${ }^{8}$ Section of Pediatric Oncology and Blood and Marrow Transplant, Alberta Children's Hospital, Calgary, Alberta, Canada.

${ }^{9}$ Section of Nephrology, Alberta Children's Hospital, Calgary, Alberta, Canada. ${ }^{10}$ Department of Emergency Medicine, University of Calgary, Calgary, Alberta, Canada. ${ }^{11}$ Department of Community Health Sciences, University of Calgary, Calgary, Alberta, Canada. ${ }^{12}$ Department of Family Medicine, University of Calgary, Calgary, Alberta, Canada. ${ }^{13}$ Section of Diabetes and Endocrinology, Alberta Children's Hospital, Calgary, Alberta, Canada. ${ }^{14}$ Division of Cardiology, Stollery Children's Hospital, Edmonton, Alberta, Canada.

Received: 25 January 2019 Accepted: 6 June 2019

Published online: 17 June 2019

\section{References}

1. McPherson M, Arango P, Fox H, et al. A new definition of children with special health care needs. Pediatrics. 1998;102(1 Pt 1):137-40.

2. Canadian Association of Pediatric Health Centres. A guideline for transition from Paediatric to adult health Care for Young people with special health care needs: a National Approach. Canadian Association of Pediatric Health Centres; 2016

3. Kaufman M, Pinzon J. Transition to adult care for young people with special health care needs. Paediatr Child Health. 2007;12(9):785-8.

4. Reiss J, Gibson R. Health care transition: destinations unknown. Pediatrics. 2002;110(6):1307-14

5. Callahan ST, Cooper WO. Changes in ambulatory health care use during the transition to young adulthood. J Adolesc Health. 2010:46(5):407-13.

6. Lotstein DS, Seid M, Klingensmith $G$, et al. Transition from pediatric to adult Care for Young people diagnosed with type 1 diabetes in adolescence. Pediatrics. 2013;131(4):e1062-e70.

7. Mackie AS, lonescu-lttu R, Therrien J, et al. Children and adults with congenital heart disease lost to follow-up: who and when? Circulation. 2009:120(4):302-9.

8. Samuel SM, Nettel-Aguirre A, Hemmelgarn BR, et al. Graft failure and adaptation period to adult healthcare centers in pediatric renal transplant patients. Transplantation. 2011;91(12):1380-5.

9. Van Walleghem N, Macdonald CA, Dean HJ. Evaluation of a systems navigator model for transition from pediatric to adult care for young adults with type 1 diabetes. Diabetes Care. 2008;31(8):1529-30.

10. Prestidge C, Romann A, Djurdjev O, Matsuda-Abedini M. Utility and cost of a renal transplant transition clinic. Pediatr Nephrol. 2012;27(2):295-302.

11. Chu PY, Maslow GR, von Isenburg M, Chung RJ. Systematic review of the impact of transition interventions for adolescents with chronic illness on transfer from pediatric to adult healthcare. J Pediatr Nurs. 2015;30(5):e19-27.

12. Weissberg-Benchell J, Shapiro JB. A review of interventions aimed at facilitating successful transition planning and transfer to adult care among young people with chronic illness. Pediatr Ann. 2017;46(5):e182-e7.

13. Steinbeck KS, Shrewsbury VA, Harvey V, et al. A pilot randomized controlled trial of a post-discharge program to support emerging adults with type 1 diabetes mellitus transition from pediatric to adult care. Pediatr Diabetes. 2015;16(8):634-9.

14. Loskutova NY, Tsai AG, Fisher EB, et al. Patient navigators connecting patients to community resources to improve diabetes outcomes. J Am Board Fam Med. 2016;29(1):78-89.

15. Hankins JS, Osarogiagbon $\mathrm{R}$, Adams-Graves $\mathrm{P}$, et al. A transition pilot program for adolescents with sickle cell disease. J Pediatr Health Care. 2012; 26(6):e45-e9.

16. Egan M, Anderson S, McTaggart J. Community navigation for stroke survivors and their care partners: description and evaluation. Top Stroke Rehabil. 2010;17(3):183-90. 
17. Freund KM, Battaglia TA, Calhoun E, et al. Impact of patient navigation on timely Cancer care: the patient navigation research program. J Natl Cancer Inst. 2014;106(6):dju115-dju.

18. Freeman HP. The history, principles, and future of patient navigation: commentary. Semin in Oncol Nurs. 2013;29(2):72-5.

19. Cohen E, Lacombe-Duncan A, Spalding K, et al. Integrated complex care coordination for children with medical complexity: a mixed-methods evaluation of a tertiary care-community collaboration. BMC Health Serv Res. 2012;12:366

20. Mackie AS, Rempel GR, Kovacs $A H$, et al. A cluster randomized trial of a transition intervention for adolescents with congenital heart disease: rationale and design of the CHAPTER 2 study. BMC Cardiovasc Disord. 2016;16:127.

21. Palfrey JS, Sofis LA, Davidson EJ, et al. The pediatric Alliance for coordinated care: evaluation of a medical home model. Pediatrics. 2004;113(Suppl 5): 1507-16.

22. Mackie AS, Rempel GR, Kovacs AH, et al. Transition intervention for adolescents with congenital heart disease. J Am Coll Cardiol. 2018;71(16): 1768-77.

23. Luke A, Doucet S, Azar R. Paediatric patient navigation models of care in Canada: an environmental scan. Paediatr Child Health. 2018;23(3):e46-55.

24. Dohan D, Schrag D. Using navigators to improve care of underserved patients. Cancer. 2005;104(4):848-55.

25. Wells KJ, Battaglia TA, Dudley DJ, et al. Patient navigation: state of the art or is it science? Cancer. 2008;113(8):1999-2010.

26. Etikan I, Musa SA, Alkassim RS. Comparison of convenience sampling and puposive sampling. Am J Theor Appl Stat. 2016;5(1):1-4.

27. Samuel S, Dimitropoulos G. Innovations in transition to adult care: solutions for a complex problem. Maternal newborn child and young people strategic clinical network transition working group meeting; 2017; Calgary.

28. Lambert SD, Loiselle CG. Combining individual interviews and focus groups to enhance data richness. J Adv Nurs. 2008;62(2):228-37.

29. Malterud K, Siersma VD, Guassora AD. Sample size in qualitative interview studies: guided by information power. Qual Health Res. 2016;26(13):1753-60.

30. Braun V, Clarke V. Using thematic analysis in psychology. Qual Res Psych. 2006;3(2):77-101

31. Guest G, MacQueen KM, Namey EE. Applied thematic analysis. Thousand Oaks, CA: SAGE Publications; 2012.

32. Elliott RF, Fischer CT, Rennie DL. Evolving guidelines for publication of qualitative research studies in psychology and related fields. $\mathrm{Br} J \mathrm{Clin}$ Psychol. 1999:38:215-29.

33. Elo S, Kääriäinen M, Kanste $\mathrm{O}$, Pölkki T, Utriainen K, Kyngäs H. Qualitative content analysis: a focus on trustworthiness. SAGE Open. 2014;4(1): 2158244014522633.

34. Guevara JP, Rothman B, Brooks E, et al. Patient navigation to facilitate early intervention referral completion among poor urban children. Fam Syst Health. 2016;34(3):281-6.

35. Anderson JE, Larke SC. Navigating the mental health and addictions maze: a community-based pilot project of a new role in primary mental health care. Mental Health Fam Med. 2009:6(1):15-9.

36. Natale-Pereira A, Enard KR, Nevarez L, Jones LA. The role of patient navigators in eliminating health disparities. Cancer. 2011;117(15 Suppl): 3543-52.

37. Percac-Lima S, Milosavljevic B, Oo SA, et al. Patient navigation to improve breast Cancer screening in Bosnian refugees and immigrants. J Immigr Minor Health. 2012:14(4):727-30.

38. Hendren S, Chin N, Fisher S, et al. Patients' barriers to receipt of Cancer care, and factors associated with needing more assistance from a patient navigator. J Natl Med Assoc. 2011;103(8):701-10.

39. Shaw KL, Southwood TR, McDonagh JE. User perspectives of transitional care for adolescents with juvenile idiopathic arthritis. Rheumatology. 2004 43(6):770-8.

40. Valenzuela JM, Vaughn LM, Crosby LE, Strong H, Kissling A, Mitchell MJ. Understanding the experiences of youth living with sickle cell disease: a photovoice pilot. Family Community Health. 2013;36(2):97-108.

41. Al-Yateem N. Child to adult: transitional care for young adults with cystic fibrosis. Br J Nurs. 2012;21(14):850-4.

42. Muller-Kagi E, Albisetti M, Koppitz AL. Adherence to treatment in adolescents with heamophilia: a qualitative study. J Hemoph Pract. 2014; $1(2): 15-20$.

43. McBrien KA, Ivers $N$, Barnieh $L$, et al. Patient navigators for people with chronic disease: a systematic review. PLoS One. 2018;13(2):e0191980.
44. Kieckhefer GM, Trahms CM. Supporting development of children with chronic conditions: from compliance toward shared management. Pediat Nurs. 2000;26(4):354-81.

45. Blum RW, Garell D, Hodgman $\mathrm{CH}$, et al. Transition from child-centered to adult health-care systems for adolescents with chronic conditions. A position paper of the Society for Adolescent Medicine J Adolesc Health. 1993;14(7):570-6.

46. Mazurek MO, Brown R, Curran A, Sohl K. ECHO autism: a new model for training primary care providers in best-practice Care for Children with Autism. Clin Pediatr. 2016;56(3):247-56.

47. Schraeder KE, Brown JB, Reid GJ. Perspectives on monitoring young people with ongoing mental health problems in primary health care: family physicians are "out of the loop". J Behav Health Serv Res. 2018:45(2):219-36.

48. McLaughlin SE, Machan J, Fournier P, et al. Transition of adolescents with chronic health conditions to adult primary care: factors associated with physician acceptance. J Pediatr Rehab Med. 2014;7(1):63-70.

49. Bhawra J, Toulany A, Cohen E, Hepburn CM, Guttmann A. Primary care interventions to improve transition of youth with chronic health conditions from paediatric to adult healthcare: a systematic review. BMJ Open. 2016; 6(5):1-8.

50. O'Brien D, Harvey K, Howse J, Reardon T, Creswell C. Barriers to managing child and adolescent mental health problems: a systematic review of primary care practitioners' perceptions. Br J Gen Pract. 2016;66(651):e693-707.

51. Okumura MJ, Kerr EA, Cabana MD, Davis MM, Demonner S, Heisler M. Physician views on barriers to primary Care for Young Adults with Childhood-Onset Chronic Disease. Pediatrics. 2010;125(4):e748-54.

52. Scal P. Transition for youth with chronic conditions: primary care physicians' approaches. Pediatrics. 2002;110(6 Pt 2):1315-21.

\section{Publisher's Note}

Springer Nature remains neutral with regard to jurisdictional claims in published maps and institutional affiliations.

Ready to submit your research? Choose BMC and benefit from:

- fast, convenient online submission

- thorough peer review by experienced researchers in your field

- rapid publication on acceptance

- support for research data, including large and complex data types

- gold Open Access which fosters wider collaboration and increased citations

- maximum visibility for your research: over $100 \mathrm{M}$ website views per year

At $\mathrm{BMC}$, research is always in progress.

Learn more biomedcentral.com/submissions 